\title{
Testing otter board hydrodynamic performances in wind tunnel facilities
}

\author{
Fernando Mellibovsky ${ }^{\mathrm{a}, *}$, Joana Prat $^{\mathrm{b}}$, Emilio Notti ${ }^{\mathrm{c}}$, Antonello Sala ${ }^{\mathrm{c}}$ \\ ${ }^{a}$ Castelldefels School of Telecom and Aerospace Engineering, Universitat Politècnica de \\ Catalunya, Castelldefels, 08860, Spain \\ ${ }^{b}$ EPSEVG-SARTI, Universitat Politècnica de Catalunya, Dept. Matemàtica Aplicada 4, \\ Vilanova i la Geltrú, 08800, Spain \\ ${ }^{c}$ National Research Council (CNR), Institute of Marine Sciences (ISMAR), 60125,
} Ancona, Italy

\begin{abstract}
The feasibility and potential advantages of wind tunnel testing of otter board designs is assessed. Traditional flume tank tests incur high operational costs and present some limitations in terms of flexibility and accuracy. Modern flume tanks, despite more flexible and accurate, are still expensive to operate or hire. Wind tunnel facilities are widespread, with a potential for low budget tests, and allow for an accurate control of velocity, angle of attack and sideslip as well as precise measurement of forces and moments in all three axes. A complete description of otter board hydrodynamics is paramount to optimising design and rigging and for the design of active control strategies that allow for stable trawling at a target speed and depth. We describe in detail the methodology of wind tunnel tests applied to general otter board designs, exemplify it with a commercial pelagic otter board and provide a comparison with existing flume tank results for the same design.
\end{abstract}

Keywords: wind tunnel, otter board, hydrodynamics, trawl gear

\section{Introduction}

Otter boards or trawl doors are key components of trawl gears for their effective and efficient use [30,24]. Their main role consists in keeping the net open at the required wing-end spread -and depth in pelagic trawling- while

\footnotetext{
${ }^{*}$ Corresponding author. email: fernando.mellibovsky@upc.edu
} 
producing the minimum possible impact in terms of trawler fuel consumption $[38,5,25]$ and, in the case of bottom otter boards, sea bottom disruption. Otter boards must also ensure stable shooting and handling of the gear [10].

Trawl doors fulfil their net-opening part through the generation of an hydrodynamic lift force at the cost of introducing a drag force that adds to the total resistance the trawler must overcome. As a result, a low lift to drag ratio of the otter board results in high trawler consumption. The trawl door lift is mainly used in keeping the net open and, when fishing in shallow waters, also in overcoming its own weight. In deep waters, the warp takes most of the reponsibility for balancing the otter board weight. Drag can be mainly ascribed to three sources: friction, wake and wing tip vortices. Friction drag is chiefly dependent on the laminar or turbulent nature of the boundary layer. Wake drag, also known as pressure or form drag, is a consequence of boundary layer separation due to adverse pressure gradients on the outer surface recompression area when generating lift. It is thus also critically dependent on the laminar or turbulent nature of the boundary layer, which conditions separation, and increases with the square of lift. Finally, wing tip vortices are responsible for the so-called lift-induced drag, which is also proportional to lift squared and inversely proportional to the aspect-ratio of the otter board. It is therefore clear that drag can be reduced both through diminishing lift requirements or by increasing the hydrodynamic efficiency through increasing the aspect-ratio. In shallow water fishing, minimising lift requires light otter boards, while in deep water heavy otter boards are preferred to enforce depth upon the net. The aspect-ratio is not only limited by practical and technical issues, but also because friction is negatively influenced by slenderness. All in all drag minimisation for the required lift is then achieved through careful hydrodynamic design and optimal rigging. While classic otter boards used to work with the outer surface in complete stall to ensure stability [31, 32], modern otter boards tend to feature slotted cambered airfoil shapes deployed in high aspect-ratio wings to stably operate in conditions closer to that of optimal efficiency. In pelagic systems, otter boards may also serve a trawl gear pilot/control task [29, 35], which renders accurate modelling essential to anticipate stability issues under realistic conditions. Other processes such as seabed impact or capture targeting are strongly affected by the dynamic interactions of vessel, rigging, otter board and net interactions, with the otter boards having a first order effect.

Trawl net opening and depth control, system stability to manoeuvring, trawl gear response to external perturbations such as currents or underwater 
gusts, etc, rely on a deep understanding of the dynamics of the system as a whole and a realistic model of the otter boards must necessarily include an accurate description of their hydrodynamic behaviour [41]. Moving parts aside, as may be devised for control purposes, this translates into the precise knowledge of how forces and moments in all three axes depend on the two relevant hydrodynamic angles: the angle of attack and the sideslip angle.

Most experimental efforts have been devoted to analysing net hydrodynamics both by means of sea trials $[47,37,12,13,9,4,21]$ and flume tank experiments of scaled net models $[26,11,16]$. There also exist studies that compare flume tank results with full-scale sea trial data for both isolated nets and full gear $[50,13,18]$. In addition, a number of numerical models to simulate net dynamics have been developed $[3,23,27,49,34,44,20]$, and also some models of complete gears, including a crude [19] or somewhat fair $[14,33]$ description of trawl door behaviour, have been devised. A careful literature search shows that the first and only full trawl gear simulation embodying thorough modelling of the otter boards was undertaken by [35].

Traditionally, the study of otter board hydrodynamics has been limited to the mere determination of the drag and lift coefficients as a sole function of the angle of attack [1,43]. These coefficients are usually obtained via reduced-scale tests in flume tank facilities [28, 15, 39]. The traditional rigging in flume tanks, with the otter board held in place by cables, results in low positioning accuracy and force measurements lack in precision. Modern flume tank facilities have improved on traditional techniques (SINTEF Fisheries, Hirtshals) by plunging the otter board in a precise orientation and measuring forces and moments with a six component balance. The downside is their operation cost and the inability of reaching water speeds that ensure dynamical similarity with real conditions. Wind tunnel testing has seldom been used in analysing trawl door hydrodynamics [6, 42, 32, 36, 22], despite a number of evident advantages. The use of wind tunnel facilities is a natural step that follows the analysis of trawl doors in the framework of underwater flight mechanics [6, 41, 29, 31]

To achieve dynamic similarity with a given otter board model, the balance in a flume tank has to endure forces six times those in a wind tunnel. Although the power required to drive the water through the flume tank is about half that required in a wind tunnel of equal cross-section, the fact is that flume tanks are invariably much larger in order to be able to accomodate tests of other marine equipment, such as fishing nets, making them oversized for otter board testing, which entails unreasonably large power consumption. 
Otter board hydrodynamics at sea are extremely difficult to test and very few studies have attempted at measuring forces in real operation [39]. Numerical modelling with CFD is a powerful alternative to produce hydrodynamic coefficients, but is computationally very costly and still needs experimental validation $[48,17,45]$.

In this paper we explore the potential benefits of exploiting wind tunnel facilities in analysing trawl door hydrodynamics, taking advantage of the ability to accurately set wind velocity and otter board orientation and to measure forces and moments in all three axes. We set up a methodology that can be exploited generally and exemplify it with a production pelagic otter board that we test at the wind tunnel facility of MariKom in Rostock, Germany. The paper is then structured as follows: The methodology for wind tunnel operation and data obtention is described in $\S 2.1$, together with reference frame definitions and similarity considerations for experimental validity. $\$ 2.2$ is devoted to data processing and hydrodynamic performance parameters extraction. Test results for a production otter board are presented in $\S 3$ and compared with flume tank results available in the literature. Finally, in $\S 4$ we summarise the pros and cons of wind tunnel exploitation and provide some recommendations for future development.

\section{Material \& Methods}

\subsection{Wind tunnel testing methodology}

Analysing otter board designs via wind tunnel testing requires careful planning. Geometrical data of the trawl door model that will be tested sets the basis for deciding on how the wind tunnel is to be operated. This data, along with wind tunnel and balance specs must be used to exploit experimental data in a meaningful way.

In this section we provide the model and wind tunnel data that is relevant to such tests, along with some similarity considerations that must be taken into account to guarantee the validity of the experiments. The analysis procedure is described in detail.

While most of the methodology discussed is generic to any wind tunnel test of an otter board, some details are specific to the particular wind tunnel setup. In our case, the experiments were performed in the MariKom (http://www.marikom.uni-rostock.de/en/) wind tunnel facilities, located at the Rostock University campus in Germany. The wind tunnel is of the Göttingen construction type (also known as Prandtl type or closed return 
wind tunnel) and provides a three-axes positioning system and a six-component balance for force and moment measurement.

\subsubsection{Trawl door model data}

The model is a scaled faithful version of the full-size trawl door. A number of geometrical parameters of the model need be considered for data processing. These parameters are summarised in Table 1 and shown in Figure 1a. Our tests will be demonstrated on a Thyborøn vf 15 pelagic trawl door (http://www.thyboron-trawldoor.dk/), whose specific dimensions will be duly introduced in $\S 3$.

The span line $(b)$ is defined as the straight line connecting both flap tips at their respective trailing edges. The pseudo-symmetry plane is then the plane orthogonal to the span line that contains the intersection of the flaps. The chord line $(l)$ is the straight line connecting leading and trailing edge on the pseudo-symmetry plane.

\subsubsection{Reference frames and wind tunnel test data}

Three different frames of reference are required to properly analyse trawl door hydrodynamic behaviour and wind tunnel results. The Earth or, in our case, wind tunnel reference frame is defined as $\mathcal{E}=\left\{\mathbf{E} ; \mathbf{x}_{e}, \mathbf{y}_{e}, \mathbf{z}_{e}\right\}$, with the origin $\mathbf{E}$ on the balance attachment point and, to construct the orthonormal basis, $\mathbf{x}_{e}$ follows the streamwise direction of the wind tunnel, pointing forward, $\mathbf{y}_{e}$ follows the horizontal spanwise wind tunnel direction, pointing rightwards, and $\mathbf{z}_{e}$ is the vertical axis pointing downwards in the direction of gravity.

The body reference frame, attached to the trawl door model, is defined as $\mathcal{B}=\left\{\mathbf{O} ; \mathbf{x}_{b}, \mathbf{y}_{b}, \mathbf{z}_{b}\right\} \equiv\{\mathbf{O} ; \mathbf{x}, \mathbf{y}, \mathbf{z}\}$, with the origin $\mathbf{O}$ placed on the chord line at its trailing edge, $\mathbf{x}$ following the chord line in the forward direction, $\mathbf{y}$ orthogonal to $\mathbf{x}$ and on the pseudo-symmetry plane, pointing outwards, and $\mathbf{z}$ completing the orthonormal basis (spanwise, pointing towards the bottom flap).

Aerodynamic forces and moments depend on air density, on the model size and shape, and on its velocity with respect to the surrounding fluid (the so called aerodynamic velocity, $\mathbf{V}^{a}$ ). The aerodynamic velocity vector is used to define a third reference frame dubbed the aerodynamic frame $\mathcal{A}=\left\{\mathbf{O} ; \mathbf{x}_{a}, \mathbf{y}_{a}, \mathbf{z}_{a}\right\}$ with $\mathbf{x}_{a}$ in the direction of $\mathbf{V}^{a}$, pointing forward, $\mathbf{y}_{a}$ orthogonal to $\mathbf{x}_{a}$, on the pseudo-symmetry plane, pointing outwards and $\mathbf{z}_{a}$ 
completing the orthonormal basis. In a wind tunnel test with experimental velocity $V,\left\|\mathbf{V}^{a}\right\|=V$ and $\mathbf{x}_{a} \equiv \mathbf{x}_{e}$.

Three angles are required to describe the orientation of the otter board with respect to the earth reference frame. The choice here will be the usual Tait-Bryan angles (sometimes mistakenly called Euler angles) yaw $(\psi)$, pitch $(\theta)$ and roll $(\phi)$. Figure 2 a shows the three rotations that take vectors from wind tunnel axes to body axes. The transformation matrix from $\mathcal{B}$ to $\mathcal{E}$ takes the form

$$
\mathcal{R}(\psi, \theta, \phi)=\left(\begin{array}{ccc}
c_{\theta} c_{\psi} & s_{\phi} s_{\theta} c_{\psi}-c_{\phi} s_{\psi} & c_{\phi} s_{\theta} c_{\psi}+s_{\phi} s_{\psi} \\
c_{\theta} s_{\psi} & s_{\phi} s_{\theta} s_{\psi}+c_{\phi} c_{\psi} & c_{\phi} s_{\theta} s_{\psi}-s_{\phi} c_{\psi} \\
-s_{\theta} & s_{\phi} c_{\theta} & c_{\phi} c_{\theta}
\end{array}\right)
$$

where $c_{x}$ and $s_{x}$ denote cosine and sine, respectively, of the angle indicated by the subscript $x$.

As shown in Figure 2b only two angles are required to define the orientation of the door with respect to the aerodynamic frame, namely the angle of attack $(\alpha)$ and the sideslip angle $(\beta)$. Rotations that preserve the aerodynamic angles (i.e rotations around $\mathbf{x}_{a}$ ) result in a mere rotation of the aerodynamic forces and moments, their projection on aerodynamic axes remaining unaltered. The transformation matrix from $\mathcal{A}$ to $\mathcal{B}$ is

$$
\mathcal{S}(\alpha, \beta)=\left(\begin{array}{ccc}
c_{\beta} c_{\alpha} & s_{\alpha} & -s_{\beta} c_{\alpha} \\
-c_{\beta} s_{\alpha} & c_{\alpha} & s_{\beta} s_{\alpha} \\
s_{\beta} & 0 & c_{\beta}
\end{array}\right)
$$

The trawl door model was tested in the wind tunnel standing on its lower shoe (see Figure 1b). The installation roll angle of the model has a value $\phi^{e}$ that is generally non zero. This angle, which stays constant throughout the experiment, together with the two additional angles the wind tunnel allows to sweep (yaw and pitch angles), conform the set of Euler angles that allow projection of measured forces and moments in body axes.

Generally speaking, the $\mathcal{E}$ and $\mathcal{A}$ reference frames are linked through the direction of the wind, the trawl door ground velocity vector and the trawl door orientation. In the case of a wind tunnel test, the relation simplifies greatly, as the door is quiescent and the wind is strictly in the direction of the wind tunnel axis. Under these conditions there exists a direct relation between the orientation angles $(\psi, \theta, \phi)$ and the aerodynamic angles $(\alpha, \beta)$ 
that is given by the following simple expression:

$$
\begin{aligned}
& \alpha=\operatorname{atan} 2\left(-\mathcal{R}_{12}, \mathcal{R}_{11}\right), \\
& \beta=\operatorname{atan} 2\left(\mathcal{R}_{13}, \mathcal{R}_{11} \cos \alpha-\mathcal{R}_{12} \sin \alpha\right),
\end{aligned}
$$

where atan2 is the 4-quadrant inverse tangent, and the subscripts indicate the rotation matrix element to be considered.

The model must be held in the wind tunnel test section from an attachment point (A), as shown in Figure 1. In our tests, we can choose to fit an adapter that holds the model at a certain distance from the ground, and that connects it to the balance origin $(\mathbf{E})$ where all forces and moments are referred. The adapter, shown in Figure 3 is meant to both separate the model from the wind tunnel walls and to allow changing the model orientation straightforwardly.

The position vector of $\mathbf{A}$ relative to $\mathbf{O}$ ( see Figure $3 \mathrm{~b}$ ) is the key to properly translating wind tunnel measurements into trawl door performance results. In our case it can be expressed, in body coordinates (indicated by the superscript), as:

$\mathbf{r}_{\mathbf{O A}}^{b}=\xi_{x} \mathbf{i}+\left[\left(b_{b}+\xi_{z}\right) \sin \Lambda_{b}-\xi_{y} \cos \Lambda_{b}\right] \mathbf{j}+\left[\left(b_{b}+\xi_{z}\right) \cos \Lambda_{b}+\xi_{y} \sin \Lambda_{b}\right] \mathbf{k}$.

The wind tunnel balance provides forces and moments in the wind tunnel reference frame as applied to its origin, E. The trawl door may be mounted standing directly on top of this point, in which case only the yaw angle can be set at will and aerodynamic ground effects will play their part. This is desirable in the case of bottom otter boards, whose actual operation takes place in direct contact with the ground thus precluding the occurrence of wing tip vortices. Nevertheless, the effect of the ground is only partially accounted for, since only tip flow blockage is considered and not the ground-door relative velocity effects that introduce boundary layers in the wind tunnel that are not present in real conditions. In the case of pelagic or semipelagic flying trawl doors, ground effects are utterly undesirable and it becomes mandatory to separate the model from the ground via the aforementioned adapter. The adapter has the further advantage of allowing for a second degree of freedom which corresponds to setting the pitch angle. The combination of yaw and pitch variation grants the opportunity to study the model in all possible working conditions from an hydrodynamic standpoint.

Figure 3a shows the adapter, which is an articulated elbow whose bottom arm of length $a_{b}$ coincides with the $\mathbf{z}_{e}$ axis and that can rotate about it 
introducing yaw, $\psi$. This rotation is automatically piloted from the wind tunnel control cabin. The top arm, which is bound to the trawl door through the attachment point, has length $a_{t}$ and can be tilted with respect to the bottom arm. If the trawl door foot is conveniently aligned as in Figure 3b the tilt directly introduces pitch, $\theta$. The pitch must be introduced manually, thus requiring a halt of the wind tunnel every time it is to be modified. The roll angle, which is fixed as discussed in Figure 1b, is $\phi^{e}$. Then, the triad $\left(\psi, \theta, \phi^{e}\right)$ are the orientation angles of the model during the wind tunnel test.

Using the orientation angles of the otter board the position vector of the attachment point $\mathbf{A}$ relative to $\mathbf{E}$ is straightforwardly expressed (see Figure $3 \mathrm{~b}$ ). In wind tunnel coordinates it reads

$$
\mathbf{r}_{\mathbf{E A}}^{e}=-a_{t} s_{\theta} c_{\psi} \mathbf{i}-a_{t} s_{\theta} s_{\psi} \mathbf{j}-\left(a_{t} c_{\theta}+a_{b}\right) \mathbf{k} .
$$

where $a_{t}=0.06 \mathrm{~m}$ and $a_{b}=0.109 \mathrm{~m}$ are the arms length of the adapter we have employed in the experiments.

\subsubsection{Similarity considerations}

A number of constraints in setting experimental parameters must be observed in order to obtain wind tunnel results that can be extrapolated to the hydrodynamic behaviour of actual trawl doors. This is called similarity, and requires that a set of representative nondimensional parameters be kept constant for nondimensional groupings resulting from dimensional analysis to be preserved from experiment to reality.

The first obvious constraint is geometrical similarity, which requires that the shape of the model matches exactly the full-scale otter board and that the attitude (aerodynamic orientation) of the door in the tests mimics the real conditions we want to emulate.

The relevant physics of trawl door flight in water involve convective and viscous transport of momentum. The nondimensional number comparing their relative importance is the Reynolds number:

$$
R e=\frac{V l}{\nu},
$$

where $V$ is the relative velocity of otter board and fluid, $l$ is a characteristic length of the otter board (e.g. the chord) and $\nu=\mu / \rho$ is the kinematic viscosity of the fluid, with $\mu$ and $\rho$ the dynamic viscosity and the mass density, respectively. Models will be smaller than full-size otter boards and 
air viscosity is about 15 times higher than water. All in all, the wind tunnel must be run at speeds higher than the actual velocity of trawl doors in water.

Temperature effects (heat conduction and convection within the fluid) can be dismissed so that the energy equation plays no important role and the Prandtl number can be ignored.

Also compressibility can be ignored, since water is incompressible and practical wind tunnel velocities are well within the incompressible airflow regime. Compressibility effects act as a lower limit for the model dimensions relative to full-scale. Mach similarity can be considered fulfilled as long as the wind tunnel is run below Mach 0.3, which sets an upper limit to air speed and, consequently, a lower bound on model scale if Reynolds similarity is to be preserved.

Cavitation can be discarded as long as the pressure on the otter boards and in the wake does not fall below water vaporisation conditions, which is rarely the case in usual trawling conditions.

Finally, Froude similarity becomes crucial whenever external volume forces such as the gravity force are important, as would be the case for partially submerged moving bodies due to wave phenomena associated to the free surface. Trawl doors are fully submerged so that Froude similarity plays no important role.

For a thorough discussion on similarity we refer the reader to [2]. Application to the field of fluid dynamics can be found in any classical fluid dynamics book such as [40].

\subsubsection{Wind tunnel test output data}

The raw dataset is loaded from a file and separated into three sets of measurements depending on the nominal wind tunnel air velocity at which they were taken. Thus, the data is split into measurements at zero velocity, at the experiment velocity and, possibly, at one or more different velocities for Reynolds similarity validation.

Every experimental point, defined by a triad $(V, \psi, \theta)$, has a corresponding zero-wind velocity measurement at $(0, \psi, \theta)$. This is required to subtract the forces and moments caused by the weight of the model.

The data acquisition process would be extremely slow if the wind tunnel was to be run and then stopped for each pair $(\psi, \theta)$. The alternative approach of sweeping all angles with the wind tunnel on and then again with the wind tunnel off has the drawback of introducing some variability in the actual values of the angles from experiment to reference. An accurate treatment of 
the data thus produced requires interpolation, which also introduces error. Taking advantage of the fact that $\psi$ is automatically swept and accurately measured while $\theta$ is changed manually and measured by hand so that the wind tunnel must be stopped, the compromise solution adopted was to alternate reference (zero-wind) and experimental (wind on) $\psi$-sweeps for every tested $\theta$. In this way, $\theta$ was kept constant from reference to experiment and $\psi$ only approximately constant but to a high degree of accuracy. Delaunay tesselation [7] followed by linear baricentric interpolation was nevertheless used for a more accurate treatment and to deal with repeated measurements of the same experimental point.

Experimental measurements are taken on a regular $(\psi, \theta)$ grid, with the wind tunnel airspeed set to the nominal experiment velocity. As already stated, $\psi$ is automatically swept while $\theta$ requires stopping the wind tunnel and then tilting the adapter manually to the desired value. The relevant output data is averaged over a sufficiently long time lapse after the instantaneous probe signals have stabilised onto a steady state for every single experimental datapoint. Each datapoint consists then of an array of values providing the information detailed in Table 2.

With this dataset, the Reynolds number can be computed for each experimental point following a simple procedure. First air density $\rho$ is calculated from air pressure and temperature using the ideal gas law state equation $\rho=p /(r T)$, where $r=287.14 \mathrm{~J} /(\mathrm{kg} \mathrm{K})$ is the gas constant for dry air, $p$ is the barometric pressure and $T$ the air temperature. Then actual velocity, $V$, is computed via Bernoulli's equation for incompressible flow $V=\left[\Delta p /\left(\rho\left(1-1 / A_{r}\right)\right)\right]^{\frac{1}{2}}$, with an error smaller than $1 \%$ for velocities over $20 \mathrm{~m} / \mathrm{s}$, where $\Delta p$ is the pressure drop in the nozzle and $A_{r}=7.98$ is the area ratio across measurement sections. Air viscosity $\mu$ is then computed using Sutherland's law $\mu=\mu_{0}\left(T_{0}+C\right) /(T+C)\left(T / T_{0}\right)^{3 / 2}$, where $T_{0}=291 \mathrm{~K}$, $C=120 \mathrm{~K}$ and $\mu_{0}=18.27 \mu \mathrm{Pas}$ for air. The Reynolds number is finally calculated using (6).

If Reynolds similarity cannot be exactly matched, it is advisable, whenever possible, a second set of measurements at a different air speed. All trawl doors tested have been subject to a different air speed for at least the zeropitch condition in order to assess how similarity mismatch may have affected the accuracy of results. 


\subsection{Methodology of data processing}

Processing the experimental data requires successive correction for the various known sources of systematic deviation, namely the effect of gravity and the aerodynamic forces acting on the adapter. The resulting net forces and moments, which are obtained in the Earth (wind tunnel) reference frame, must then be translated to a convenient point on the door and projected in body and/or aero axes to be of any use. Finally, forces and moments are rendered without dimensions and Reynolds effects assessed whenever sufficient data is available.

\subsubsection{Adapter data loading}

The adapter holding the trawl door in position is subject to aerodynamic forces. This induces primarily drag and pitching moment, but it may also have some other effects. To properly isolate the aerodynamic forces on the trawl door, the adapter contribution must be duly subtracted. There is no exact way of doing so, since interference drag (the additional force -that need not be additive- that comes from the interaction of two bodies immersed in the same airflow) may have its effect. Nevertheless, the soundest approach is to neglect interference drag, measure the effect of the adapter alone and subtract it from measurements on the door plus adapter together.

To do so, an additional set of data, providing the same parameters, has been measured for the adapter alone. This could have been done for varying pitch and yaw angles, but it was deemed unnecessary and only yaw, which can be automatically swept, was considered. At least two different velocities must be tested to be able to subtract adapter effects extrapolated from a velocity that is close to actual experiment velocity.

\subsubsection{Experimental data processing}

The effects of gravity are removed by subtraction of zero-wind forces and moments from the experimental point forces and moments:

$$
\hat{\mathbf{X}}(V, \psi, \theta)=\tilde{\mathbf{X}}(V, \psi, \theta)-\tilde{\mathbf{X}}(0, \psi, \theta)
$$

where $\mathbf{X}=\left(\mathbf{F}^{e}, \mathbf{M}_{\mathbf{E}}^{e}\right)$, the tilde denotes wind tunnel raw data and the hat corresponds to data corrected for weight, $V$ is the velocity and $(\psi, \theta)$ the orientation angles.

Pitch is not varied from the experiment to the reference such that the

subtraction could be direct. Yaw, however, may have little differences since 
the wind tunnel is not stopped to take reference measurements after data acquisition at each yaw angle. Two approaches are possible at this stage. The subtraction may be done directly by using nominal yaw and pitch angles for reference selection or Delaunay tesselation (triangulation in our 2-parameter interpolation) followed by linear baricentric interpolation used to correct for reference yaw deviation from experiment. The latter has the additional advantage that the subtraction can be done even where there is more than one acquisition for the same experimental point, since triangulation allows for automatic interpolation of a cloud of data that is not organised on a regular grid. This is the approach that we have taken in the present work.

The adapter aerodynamic results are corrected for gravity in the same way experimental results are:

$$
\hat{\mathbf{X}}_{a}(V, \psi)=\tilde{\mathbf{X}}_{a}(V, \psi)-\tilde{\mathbf{X}}_{a}(0, \psi),
$$

the subindex $a$ denoting adapter data. Since the main effect of the adapter is to increase drag slightly and this is not strongly dependent on yaw and pitch angles, a single datapoint would suffice for applying the correction. Given that changing yaw is automatic and thus fast, though, the adapter aerodynamic forces and moments have been tested for varying yaw, while pitch effects have been dismissed as irrelevant. Once the net effect of gravity has been subtracted, the adapter aerodynamic forces and moments are ready to be used for correction of experimental results.

The adapter correction is slightly more involved than gravity correction. Not only an adequate adapter reference must be chosen or duly interpolated to match experimental yaw conditions (pitch is ignored here), but also ambient pressure and temperature may have changed and, more importantly, the wind tunnel velocity may have been different, especially if the adapter was tested before the actual experiment. It makes no sense testing the adapter after every trawl door experiment, so the adapter is tested once and for all and these unique results used for correction. To account for eventual temperature, pressure and velocity variations from adapter reference tests to actual experiments, the subtraction must be carried out following

$$
\mathbf{X}(V, \psi, \theta)=\hat{\mathbf{X}}(V, \psi, \theta)-\frac{\rho V^{2}}{\rho_{a} V_{a}^{2}} \hat{\mathbf{X}}_{a}(V, \psi),
$$

with the correction directly linked to dynamic pressure change from each reference data point to the corresponding experimental data point. 
The forces and moments thus obtained, $\mathbf{F}^{e}=\left(F_{x}^{e}, F_{y}^{e}, F_{z}^{e}\right)$ and $\mathbf{M}_{\mathbf{E}}^{e}=$ $\left(M_{x}^{e}, M_{y}^{e}, M_{z}^{e}\right)$ respectively, are obviously given in wind tunnel axes and relative to their origin $\mathbf{E}$ in the test section ground where the adapter is mounted. They must be translated to a convenient fixed point on the door so that the hydrodynamic behaviour of the otter board can be evaluated.

The point chosen here, for its straightforward location on any given trawl door, is $\mathbf{O}$ (see Figure 1b). Force is directly translated to this point, while moment requires the addition of the moment produced by this force to the moment measured by the balance with respect to $\mathbf{E}$ :

$$
\mathbf{M}_{\mathbf{O}}^{e}=\mathbf{M}_{\mathbf{E}}^{e}+\mathbf{F}^{e} \times \mathbf{r}_{\mathbf{E O}}^{e},
$$

with $\mathbf{r}_{\mathbf{E O}}^{e}$, the position of $\mathbf{O}$ in Earth coordinates, computed as

$$
\mathbf{r}_{\mathbf{E O}}^{e}=\mathbf{r}_{\mathbf{E A}}^{e}+\mathbf{r}_{\mathbf{A O}}^{e}=\mathbf{r}_{\mathbf{E A}}^{e}-\mathcal{R}\left(\psi, \theta, \phi^{e}\right) \mathbf{r}_{\mathbf{O A}}^{b},
$$

where $\mathbf{r}_{\mathbf{A O}}$ is the relative vector from $\mathbf{A}$ to $\mathbf{O}$ (see Figure $3 \mathrm{~b}$ ) and $\mathbf{r}_{\mathbf{O A}}^{b}$ and $\mathbf{r}_{\mathbf{E A}}^{e}$ are given by equations (4) and (5), respectively.

\subsubsection{Force and moment aerodynamic coefficients}

The force and moment vectors are appropriately nondimensionalised to obtain force and moment coefficient vectors using

$$
\begin{aligned}
& \mathbf{C}_{F}=\left(C_{x}, C_{y}, C_{z}\right)=\frac{1}{\frac{1}{2} \rho S V^{2}} \mathbf{F}, \\
& \mathbf{C}_{M}=\left(C_{M_{x}}, C_{M_{y}}, C_{M_{z}}\right)=\frac{1}{\frac{1}{2} \rho S V^{2} d} \mathbf{M},
\end{aligned}
$$

with $d$ the relevant lever length for each of the moment components:

$$
d=\left\{\begin{array}{lll}
b & \text { for } & C_{M_{x}}, \\
\sqrt{b^{2}+l^{2}} & \text { for } & C_{M_{y}}, \\
l & \text { for } & C_{M_{z}} .
\end{array}\right.
$$

All moment coefficients $\mathbf{C}_{M}$ and the $C_{z}$ force coefficient are usually given in body coordinates, while $C_{x}$ and $C_{y}$ have traditionally been expressed in the aerodynamic frame of reference and go by the name of drag and lift coefficient, respectively. This has been done so historically for convenience and for ease of modelling. 
The force and moment vectors with respect to $\mathbf{O}$, originally obtained in wind tunnel coordinates, are straightforwardly transformed to body coordinates using matrix $\mathcal{R}$ from equation (1):

$$
\begin{aligned}
& \mathbf{F} \equiv \mathbf{F}^{b}=\mathcal{R}^{T}\left(\psi, \theta, \phi^{e}\right) \mathbf{F}^{e} \\
& \mathbf{M}_{\mathbf{O}} \equiv \mathbf{M}_{\mathbf{O}}^{b}=\mathcal{R}^{T}\left(\psi, \theta, \phi^{e}\right) \mathbf{M}_{\mathbf{O}}^{e}
\end{aligned}
$$

Then,

$$
C_{z}=C_{z}^{b}, \quad \mathbf{C}_{M_{\mathbf{O}}}=\mathbf{C}_{M_{\mathbf{O}}}^{b} .
$$

Next, $\mathbf{F}$ is projected onto the aerodynamic frame of reference following three steps. First the aerodynamic angles are evaluated using equation (3). Then the transformation matrix $\mathcal{S}$ defined in (2) that takes from aerodynamic to body axes is computed. Finally, left-multiplying $\mathbf{F}^{b}$ with the transpose of $\mathcal{S}$ provides $\mathbf{F}^{a}$ :

$$
\mathbf{F}^{a}=\mathcal{S}^{T}(\alpha, \beta) \mathbf{F}^{b} .
$$

The lift and drag coefficients are evaluated, following the usual sign convention, as

$$
\left(C_{D}, C_{L}\right)=\left(-C_{x}^{a}, C_{y}^{a}\right)
$$

\subsubsection{Centre of pressure}

The centre of pressure, i.e. the point of application of the aerodynamic force, is readily available from the accurate knowledge of the force and moment vectors. This point is of great value to otter board manufacturers, since it provides insight into how the door must be rigged to obtain the desired performance. It is most natural to give it in body coordinates.

Given the force and the moment with respect to a point $\mathbf{P}$ on the otter board, the centre of pressure is found as the locus of points $\mathbf{C}$ with respect to which the moment cancels exactly:

$$
\mathbf{M}_{\mathrm{C}}=\mathbf{M}_{\mathbf{P}}+\mathbf{F} \times \mathbf{r}_{\mathbf{P C}}=\mathbf{0},
$$

where $\mathbf{r}_{\mathbf{P C}}$ is the position vector of $\mathbf{C}$ relative to $\mathbf{P}$.

Any vector $\mathbf{r}_{\mathbf{P C}}+\lambda \mathbf{F} /\|\mathbf{F}\|$ verifies (18) $\forall \lambda \in \mathbb{R}$, meaning that the centre of pressure is not an actual point but a line. To remove the degeneracy and reduce it to a single point, an additional condition must be imposed. We choose the condition of taking the point on the centre of pressure line that intersects with the $\mathbf{x z}$ plane:

$$
\mathbf{r}_{\mathbf{P C}}^{b} \cdot \mathbf{j}=0
$$


A more natural condition would be to ask for the point of the line that lies on the otter board surface, but this requires dealing with intricate geometric details that make the process cumbersome.

For the calculation of $\mathbf{C}$ we have chosen $\mathbf{P} \equiv \mathbf{O}$. Taking the cross product of (18) with $\mathbf{j}$, exploiting the properties of the vector triple product and condition (19), the resulting expression allows direct computation of the centre of pressure in body coordinates:

$$
\mathbf{r}_{\mathbf{O C}}^{b}=-\frac{\mathbf{M}_{\mathbf{O}}^{b} \times \mathbf{j}}{\mathbf{F}^{b} \cdot \mathbf{j}}
$$

\section{Results}

The methodology described above has been employed upon testing a Thyborøn type 15 vf. The wind tunnel test was conducted in MariKom wind tunnel facilities on October 20th 2013. The scaled model has a span $b=0.79 \mathrm{~m}$ and chord $l=0.32 \mathrm{~m}$ (area $S=0.26 \mathrm{~m}^{2}$, aspect ratio $A R=2.5$ ), with dihedral $\Lambda_{b}=\Lambda_{t}=8.5^{\circ}$. The installation roll angle when bolted to the adapter

top arm was $\phi^{e}=8.5^{\circ}$ and the attachment location in body coordinates is given by $\mathbf{r}_{\mathbf{O} A}^{b}=(0.242,0.027,0.440) \mathrm{m}$.

In the tests, the yaw angle of the adapter was swept from $\psi=0^{\circ}$ to $40^{\circ}$ in steps of $5^{\circ}$ and the pitch angle from $\theta=-10^{\circ}$ to $15^{\circ}$ in steps of $5^{\circ}$. The model was tested at the maximum admissible airspeed of $V=20 \mathrm{~m} / \mathrm{s}$ (to avoid balance overloading) with the intent of preserving Reynolds similarity as far as possible. A second set of measurements with $V=15 \mathrm{~m} / \mathrm{s}$ was also undertaken for Reynolds effects assessment.

Following the methodology of $\S 2.2$ we have obtained the aerodynamic coefficients $C_{D}, C_{L}, C_{z}, C_{M_{x}}, C_{M_{y}}$ and $C_{M_{z}}$ for both wind speeds as a function of the angle of attack $\alpha$ and sideslip angle $\beta$. The effect of wind velocity change on the coefficients remains under $2.5 \%$ for usual working angles of $5^{\circ} \leq \alpha \leq 35^{\circ}$ and $\beta=0$.

Figure 4 shows contour maps of the aerodynamic coefficients as a function of $(\alpha, \beta)$ for $V_{n}=20 \mathrm{~m} / \mathrm{s}\left(\operatorname{Re} \approx 4.6 \times 10^{5}\right)$. The coloured circles represent the actual experimental points, whose perfectly rectangular $(\psi, \theta)$ mesh deforms when considering actual $(\alpha, \beta)$ aerodynamic angles. $C_{D}$ and $C_{L}$ increase with $\alpha$ while featuring little dependence on $\beta$ for the range of sideslip angles explored. The approach of separation may be intuited at the high $\alpha$ end but has not been observed at the maximum $\alpha$ tested. A maximum $C_{D}=1.011$ 
and $C_{L}=2.3711$ is attained for $\alpha=40^{\circ}$ and $\beta=-5^{\circ} . C_{z}$ is low for $\beta=0^{\circ}$ and its distribution is non symmetric due to the slight asymmetry of the upper and bottom flaps with respect to $x y$-plane. The same goes for the pitching moment $\left(C_{M_{y}}\right)$. The roll moment $\left(C_{M_{x}}\right)$ takes moderate values while the largest effect is observed on the yaw moment $\left(C_{M_{z}}\right)$, as expected. The largest $\alpha$ becomes, the largest the yaw moment that will need compensation by the action of the warp.

Contour maps for aerodynamic efficiency $\left(\eta=C_{L} / C_{D}\right)$ are shown in figure $5 a$. As a matter of fact, the highest $C_{L}$ does not correspond to the maximum $\eta$, which is actually fairly low. This is a classical result of wing theory, which is a direct consequence of the fact that drag degrades fast with the square of lift. More modest angles of attack are preferable for high aerodynamic efficiency, the maximum $\eta=3.57$ being obtained for $(\alpha, \beta) \approx$ $(15,-5)^{\circ}$. This would be the optimal working point for a neutrally buoyant door as it would provide the trawl gear with the necessary net opening force at the minimum drag cost. $\eta$ remains high for a wide range of $\alpha$ and $\beta$ around the maximum, which ensures fairly low drag for suboptimal towing.

The location of the centre of pressure has been found using equation (20) and represented on a side view sketch of the otter board in figure $5 b$. The dependence on the angle of attack has been colour-coded, while the sizing represents variation in sideslip angle, the largest circle always corresponding to $\beta=0^{\circ}$. Table 3 quantifies this $\alpha$-dependence of the position of the centre of pressure as measured in units of chord from the body frame origin at the mid-span trailing edge. The largest effect is that of $\alpha$ through $C_{M_{z}}$, the other two coefficients having little or no effect as evident from the nearly centred $z$-location of the centre of pressure. Increasing $\alpha$ brings the centre of pressure forward toward the leading edge and slightly down on the bottom flap, with a tendency to settle slightly forward ( $\sim 40 \%$ of the the chord) from mid-chord and below the mid-span line. The effects of varying $\beta$ are moderate at low $\alpha$ and negligible at high $\alpha$. The precise location of the centre of pressure, combined with the mass distribution of the trawl door provide the means to anticipate the optimal rigging to have the otter board working as desired in real conditions.

In general, otter boards are designed to work with little or no sideslip for optimal efficiency. While it remains useful to analyse their behaviour when subject to sideslip, as otter boards will transiently adopt non negligible sideslip while manoeuvring or in non-standard sea conditions, it makes complete sense to report their performances at $\beta=0^{\circ}$. Figure $6 a$ shows a 
cut at $\beta=0^{\circ}$ through the $C_{L}, C_{D}, C_{z}$ and $\eta$ contour maps. $C_{L}$ rapidly grows with $\alpha$, initially linearly but with a tendency to saturate that indicates that stall is not far beyond $\alpha=40^{\circ}$. $C_{D}$ also grows with $\alpha$ in the parabolic typical fashion of lift-producing objects (drag polar). $C_{z}$ would be nil for a perfectly up-down symmetric otter board. Its increasing yet moderate values are a consequence of asymmetry and the fact that they are positive indicates that hydrodynamics tends to add on weight. As a matter of fact, the trawl door needs to slightly pitch nose up to cancel this effect. The fastest growth of $C_{D}$ when compared with $C_{L}$ is responsible for the existence of a maximum of $\eta$. For this otter board, the maximum for no sideslip angle is $\eta \approx 3.5$ for $\alpha \approx 15^{\circ}$.

\subsection{Comparison with flume tank tests and dynamic similarity}

To allow comparison with flume tank results, wind tunnel results must be interpolated on actual hydrodynamic angles and force coefficients projected onto the flume tank reference frame. There is a standard in flume tank tests to use otter board orientation angles $(\psi, \theta$ and $\phi$ in our notation) and call them attack angle (erroneously), pitch and heel (or roll), respectively. While drag is correctly defined as the force in the direction of flow $\left(C_{D}=-C_{x}^{f t}\right)$, lift is wrongly taken as the horizontal projection of the flow normal force $\left(C_{y}^{f t}\right.$ in our notation, with the superscript denoting projection on the flume tank frame). To allow comparison, we have translated wind tunnel results into the standard flume tank framework and plotted them together with publicly available flume tank results (http://www.thyboron-trawldoor.dk/) for the same geometry in figure $6 b$. The flume tank tests were conducted with $\phi \approx 0^{\circ}, \theta \approx 2^{\circ}$ and $\psi=\{27.6,30.0,33.6,36.8,39.2\}^{\circ}$ (K. Hansen, SINTEF, private communication).

While the trends are clearly coincident for a wide range of $\alpha$, there seems to be a systematic offset in both $C_{y}^{f t}$ and $C_{x}^{f t}$ from flume tank to wind tunnel. Flume tank produces higher lift and lower drag than wind tunnel for the whole range explored. The deviation of flume tank with respect to wind tunnel tops at $20 \%$ for the lowest $\alpha$ and reduces to under $10 \%$ at the highest $\alpha$. Notably, flume tank tests pinpoint the initiation of stall at $\alpha \approx 37^{\circ}$, while wind tunnel tests do not reflect detachment for $\alpha \leq 40^{\circ}$. Confident as we are of the preciseness of the wind tunnel results, there is a high level of uncertainty regarding flume tank tests. In the flume tank, the angle of attack (actually yaw $\psi$ ) is the angle of flume tank water flow with the shoe of the otter board [43]. For the 15 vf one would think this choice is equivalent 
to our definition with the chord line, but since the shoe is not rectangular, this would need some clarification that is missing in the tests. However, this would account for a mere $\alpha$ shift that would partially explain either $C_{L}$ or $C_{D}$ discrepancies but not both, as the curves are shifted in opposite directions. The biggest source of uncertainty is the actual attitude of the trawl door during flume tank tests. Pelagic otter boards are tested at nearly zero heel and pitch, but how accurately this is accomplished is not known. Allegedly, the pitch angle may be of up to $2^{\circ}$ and the zero heel that would correspond to a perfectly horizontal pseudo-symmetry plane is only approximately set to zero. Also the projection of forces in the flume tank frame of reference is somewhat involved and introduces error from several sources, such as cable force measurements and angles. Taking all this into consideration, we claim that the accuracy of forces measurement and projection in the wind tunnel is unrivaled by classic flume tanks. Modern flume tanks resolve this issue by incorporating 3-component balances, the advantage of wind tunnels being then merely reduced to their lower operating cost.

There exists an additional source of discrepancy that needs be taken into consideration that concerns dynamic similarity. As argued in $\S 2.1 .3$ results are representative of real otter board behaviour if Reynolds similarity is matched. The Reynolds number corresponding to the wind tunnel and flume tank tests are:

$$
R e^{w t}=\frac{V^{w t} l^{w t}}{\nu_{\text {air }}} \approx 4.6 \times 10^{5}, \quad R e^{f t}=\frac{V^{f t} l^{f t}}{\nu_{\text {water }}} \approx 2.9 \times 10^{5},
$$

where $V^{w t}=20 \mathrm{~m} / \mathrm{s}, l^{w t}=0.32 \mathrm{~m} / \mathrm{s}, V^{f t}=0.7 \mathrm{~m} / \mathrm{s}, l^{f t}=0.49 \mathrm{~m} / \mathrm{s}, \nu_{\text {water }} \approx$ $1.2 \times 10^{-6} \mathrm{~m}^{2} / \mathrm{s}$ and $\nu_{\text {air }} \approx 1.4 \times 10^{-5} \mathrm{~m}^{2} / \mathrm{s}$. The wind tunnel tests with $V^{w t}=15 \mathrm{~m} / \mathrm{s}$ correspond to $R e^{w t} \approx 3.4 \times 10^{5}$, closer but still above flume tank conditions. Anyhow, and as already mentioned, this second dataset at a lower velocity only accounts for under a $2.5 \%$ dicsrepancy in the coefficients, not sufficient to explain wind tunnel and flume tank differences.

The Reynolds number at real sea conditions takes a minimum value $R e>$ $7.9 \times 10^{5}$ for the slowest towing speed $V \approx 1.5 \mathrm{~m} / \mathrm{s}$ and smallest production otter board with $l=0.63 \mathrm{~m} / \mathrm{s}$. Usual values will be in the order of $R e=$ $O\left(10^{6}\right)$ reaching up to $5 \times 10^{6}$ for the largest version of the otter board $\left(A=20 \mathrm{~m}^{2}\right)$ and the maximum towing speed $(V=2 \mathrm{~m} / \mathrm{s})$.

In this respect, wind tunnel experiments, although still short of achieving realistic Reynolds numbers, are much closer than usual flume tank tests 
are. Some facilities allow for larger velocity and could potentially accomodate larger models, thus increasing flume tank Re. This also holds for wind tunnels, with cost clearly favouring the latter. In general, hydrodynamic coefficients are only marginally dependent on $R e$ for sufficiently small $R e$ ranges, which justifies providing a unique set of coefficients for a whole family of otter boards regardless of size and towing speed. Nonetheless, this may no longer be the case if the Re-range sweeps across the so called critical Reynolds number that characterises indistinctly bulky objects and streamlined objects at high angles of attack. Supercriticality concerns the turbulent transition of the boundary layer prior to detachment. Since turbulent boundary layers exhibit higher momentum in the immediate vicinity of the wall due to turbulent mixing, they resist better than laminar boundary layers the adverse pressure gradients the flow usually undergoes in the recompression region towards the trailing edge. This results in higher friction (due to the turbulent nature of the boundary layer) but also in a much thinner wake and consequent lower form or wake drag, which is dominant in these situations. For low aspect ratio lifting objects such as otter boards, this effect is also measurable in the lift and sideforce coefficients. Additional tests for varying Re would be required to properly identify criticality. In any case, the postponement of stall in the wind tunnel with respect to flume tank, suggests that the critical Reynolds number may lie in between.

Surprisingly, flume tank specs feature water speeds higher than actually used in otter board testing, which would result in better Reynolds similarity. We believe this might stem from a misconception of the relevant physics involved in otter board and netting hydrodynamics. Flume tank facilities have extensively been used in trawl netting tests, which basically rely on simple modeling rules [46], empirical observation [11] or Froude's law [8] for dynamic similarity to be accomplished. Bulk Reynolds number effects can be disregarded as negligible and a mere correction based on a Reynolds number defined with the net twine diameter can largely improve model to full-scale results extrapolation [16]. Froude number similarity requires that the velocity scales like the square root of the length scale, resulting in lower flume tank velocities than full-scale towing velocities. While this remains tolerable for trawl nets in terms of Reynolds similarity, it becomes critical for otter boards, as Reynolds number can get as low as to have an impact on the hydrodynamics. Unfortunately this has been systematically disregarded in flume tank otter board testing [1, section 3-7], where Froude similarity has been given priority resulting often in worryingly low Reynolds numbers that 
may completely invalidate the obtained force coefficients.

There is nevertheless an important aspect that was not considered in designing the wind tunnel tests and that would probably provide results closer to real sea conditions. Free-stream turbulence levels in wind tunnels are usually very low at $<1 \%$, while in flume tanks usually range in the 4 to $5 \%$. This favours a turbulent boundary layer from outset, which resists separation better entailing lower wake drag and at the same time leads to better current quality, allowing for increased lift. Large otter boards in real sea conditions are more likely to face these noisy conditions than those in the virtually turbulence-free airstream of wind tunnels. This can be straightforwardly solved in future wind tunnel testing of otterboards through artificially increasing preturbulence levels. This is done by using an adequate turbulence-generating grid at the entrance of the test chamber. We believe that this alone will get wind tunnel testing closer to flume tank results and, what is more important, provide better estimates of otter board performances at sea, and all this at a low cost and with good accuracy.

\section{Conclusions}

We have provided a detailed description of a procedure to undertake otter board testing in wind tunnel facilities and exemplified the method for a production trawl door for which flume tank results are available in the literature. While compatible to some extent, non negligible discrepancies are observed between flume tank and wind tunnel experiments that we resolve in favour of the latter. The differences we ascribe to the inherent uncertainty of the flume tank methodology and, more prominently, to Reynolds number effects.

The great advantage of wind tunnel experiments is their versatility, which allows for straightforward measurement of forces and moments in all three axes and at all possible hydrodynamic attitudes (as given by the two hydrodynamic angles). This is not only essential for producing useful information such as the location of the centre of pressure, which comes very handy in deciding the rigging, but also for a sufficiently accurate description of the hydrodynamics that can be built into a full trawl gear simulation for performance prediction, stability analysis or control loop design.

Furthermore, we believe that by importing concepts and definitions from aeronautics and flight mechanics, the trawl fishing community could potentially benefit from a better understanding of the hydrodynamics of otter 
boards, resulting in more efficient designs and more effective use. Using the actual hydrodynamic angles (attack and sideslip) instead of mere orientation angles and measuring all forces and moments and not just drag and spreading force is a crucial step towards fully comprehending otter board behaviour and potential for improvement. This is both possible in flume tanks duly geared with the right equipment or in wind tunnels, as demonstrated here. Nevertheless, the operating cost of modern flume tank facilities exceeds by a factor of four to six times the cost of wind tunnel operation for a comparable test comprising the same number of models in an equivalent number of possible configurations.

One of the fundamental aspects of testing is dynamic similarity. While our tests could only approach the lower Re-end of real conditions, which is already better than what flume tanks experiments have achieved for the otter board tested, there is a potential for improvement in this respect. A major, yet very simple improvement to be implemented in wind tunnel testing is the use of a turbulence-generation grid in the entrance to the test chamber. This can improve dynamic similarity with sea conditions, despite the Reynolds number discrepancy, through ensuring the turbulent nature of the boundary layers developing on the otter board surface right from onset. Slightly smaller models made of polymer or composite materials such as glass or carbon fibre to reduce weight, and mounted horizontally on the balance would help achieve higher speeds without overloading the load cells of the balance. Building a stronger balance, and/or using wind tunnels with larger test sections can help increase the Reynolds number for better matching similarity.

To account for ground proximity effects, which are irrelevant for pelagic and semipelagic trawl doors but can be important for bottom otter boards, the models can be mounted with the shoe very close to the wind tunnel ground. This would prevent bottom flap tip vortices but would not properly emulate the relative motion of trawl door and sea bottom. Some wind tunnel facilities offer the option of using a moving belt to accurately capture ground effect.

Tests for the same trawl door in a modern flume tank facility equipped with the latest measuring techniques, and in real sea trials, is currently underway and will help validate wind tunnel testing further. Also numerical simulation is to be implemented in the near future to assess its potentials.

All in all, wind tunnel facilities, used following the methodology presented in this paper, provide a flexible, accurate means of testing otter board hydrodynamic performance. 


\section{Acknowledgements}

We kindly thank Mathias Paschen, Sebastian Schreier and Christian Semlow (MariKom $\mathrm{GmbH}$ ) for their help in setting up and carrying out the wind tunnel experiments at their facilities in Universität Rostock.

We would also like to thank Jan Bundgaard (Thyboron, DK) for letting us demonstrate the method on one of their commercial otter boards and Kurt Hansen for providing detailed information on previous flume tank results for the same otter board.

This work was partially funded by the EC Commission through the Seventh Framework Programme with the Research project BENTHIS (Benthic ecosystem fisheries impact study, KBBE 2012.1.2-09, Grant Agreement Nr. 312088) and the Flagship Project RITMARE "The Italian Research for the Sea", coordinated by the Italian National Research Council and funded by the Italian Ministry of Education.

The research of Fernando Mellibovsky and Joana Prat was also sup-

ported by the Spanish Ministry of Economy and Competitivity under grant CGL201128682C0202. 


\section{References}

[1] Authority, S.F.I., IFREMER, DIFTA, 1993. Otterboard performance and behaviour. Comission of the European Communities FAR.

[2] Barenblatt, G., 1996. Scaling, self-similarity, and intermediate asymptotics. Cambridge University Press, New York.

[3] Bessonneau, J., Marichal, D., 1998. Study of the dynamics of submerged supple nets (applications to trawls). Ocean Engineering 7, 563-583.

[4] Brčić, J., Grilli, F., Sala, A., 2014. Influence of sea-bottom temperature and depth on swept area estimation from trawl surveys. Scientia Marina 78(1), 135-142.

[5] Buglioni, G., Notti, E., Sala, A., 2012. E-audit: Energy use in italian fishing vessels, in: Rizzuto, Soares, G. (Eds.), Sustainable maritime transportation and exploitation of sea resources, Taylor \& Francis Group, London.

[6] Crewe, P., 1964. Some of the general engineering principles of trawl gear design, in: Modern fishing gear of the world. Fishing news (books) Ltd., London. volume 2, pp. 165-181.

[7] Delaunay, B., 1934. Sur la sphère vide. a la mémoire de georges voronoï. Doklady Akademii Nauk SSSR. 6, 793-800.

[8] Dickson, W., 1961. A study relating models to commercial trawls. Mar. Res. Dep. Agric, Fish, Scotl. 1, 1-48.

[9] Dremire, P., Fiorentini, L., Cosimi, G., Leonori, I., Sala, A., Spagnolo, A., 1999. Escapement from the main body of the bottom trawl used for the mediterranean international trawl survey (medits). Aquatic Living Resources 12(3), 207-217.

[10] FAO, 1974. Otter board design and performance. In: Fishing Manuals. FAO, Rome.

[11] Ferro, R., vanMarlen, B., Hansen, K., 1996. An empirical velocity scale relation for modelling a design of large mesh pelagic trawl. Fisheries Research 28, 197-230. 
[12] Fiorentini, L., Dremire, P., Leonori, I., Sala, A., Palumbo, V., 1999. Efficiency of the bottom trawl used for the mediterranean international trawl survey (medits). Aquatic Living Resources 12(3), 187-205.

[13] Fiorentini, L., Sala, A., Hansen, K., Cosimi, G., Palumbo, V., 2004. Comparison between model testing and full-scale trials of new trawl design for italian bottom fisheries. Fisheries Science 70, 349-359.

[14] Folch, A., Prat, J., Antonijoan, J., Manuel, A., Sala, A., Sard, F., 2007. Simulation of bottom trawl fishing gears. A simplified physical model, in: Soares, C.G., Kolev, P. (Eds.), Maritime Industry, Ocean Engineering and Coastal Resources, Taylor and Francis Group. pp. 921-927.

[15] Fukuda, K., Hu, F., Tokai, T., Matuda, K., 1999. Effects of aspect and camber ratios on hydrodynamic characteristics of biplane-type otter board. Nippon Suisan Gakkaishi 65, 860-865.

[16] Hu, F., Matuda, K., Tokai, T., 2001. Effects of drag coefficient of netting for dynamic similarity on model testing of trawl nets. Fisheries Science $67,84-89$.

[17] Jonsson, E., 2012. Aerodynamic optimization by variable-resolution modeling and space mapping. Ph.D. thesis. Reykjavik University, Reykjavik.

[18] Kumazawa, T., Hu, F., Fuwa, S., Nagamatu, K., Kinoshita, H., Tokai, T., 2009. Model test of trawl gear with a net-mouth opening device based on modified tauti's law. Nippon Suisan Gakkaishi 75, 793-801.

[19] Lee, C., Lee, J., 2000. Modeling of a midwater trawl system with respect to the vertical movements. Fisheries Science 66, 851-857.

[20] Lee, C., Lee, J., Cha, B., Kim, H., Lee, J., 2005. Physical modeling for underwater flexible systems dynamic simulation. Ocean Engineering 32, 331-347.

[21] Lucchetti, A., Sala, A., 2012. Impact and performance of mediterranean fishing gear by side-scan sonar technology. canadian journal of fisheries and aquatic sciences. Canadian journal of fisheries and aquatic sciences 69, 1806-1816. 
[22] Mellibovsky, F., Notti, E., Prat, J., Sala, A., 2014. Assessment of hydrodynamic performance and impact of otterboards in wind tunnel trials, in: Proceedings of the International ICES Symposium on Effects of fishing on benthic fauna, habitat and ecosystem function (16-19/06/2014, Troms $\varnothing$, Norway), p. 82.

[23] Niedzwiedz, G., Hopp, M., 1998. Rope and net calculations applied to problems in marine engineering and fisheries research. Arch. Fish. Mar. Res. 46, 125-138.

[24] Notti, E., De Carlo, F., Brčić, J., Sala, A., 2013. Technical specifications of mediterranean trawl gears, in: Paschen, M. (Ed.), Contributions on the Theory of Fishing Gears and Related Marine Systems Vol. 8. Proceedings of the 11th International Workshop on methods for the development and evaluation of maritime technologies (Rostock, 9-12 October 2013), pp. 163-169.

[25] Notti, E., Sala, A., 2013. Propulsion system improvement for trawlers, in: Soares, G., Pea, L. (Eds.), Developments in Maritime Transportation and Exploitation of Sea Resources. Proceedings of the 15th International Congress of the International Maritime Association of the Mediterranean (La Corua, 14-17 October 2013), pp. 1085-1090.

[26] O’Neill, F., 1993. Small-scale modelling rules of trawl nets. Fisheries Research 18, 197-230.

[27] O'Neill, F., 1999. Axisymmetric trawl cod-ends made from netting of a generalized mesh shape. IMA Journal of Applied Mathematics 62, 245-262.

[28] Park, C.., Matuda, K., Hu, F., 1996. Effects of dihedral and sweepback angles on lift and drag of the cambered otter board. Nippon Suisan Gakkaishi 62, 920-927.

[29] Paschen, M., 1981. Beitrag zur Voraussage von Bewegungsbahnen pelagischer Schleppnetze nach Einleitung von Schiffsmanövern. Ph.D. thesis. University of Rostock, Rostock.

[30] Paschen, M., 2006. Prediction of the dynamic behaviour of pelagic trawl doors, in: Lee, C.W. (Ed.), Contributions on the Theory of Fishing Gears and Related Marine Systems Vol. 4, pp. 11-26. 
[31] Patterson, R., Watts, K., 1985. The otterboard as a low aspect-ratio wing at high angles of attack; some theoretical aspects. Fisheries Research 2, 351-372.

[32] Patterson, R., Watts, K., 1986. The otterboard as a low aspect-ratio wing at high angles of attack; an experimental study. Fisheries Research $4,111-130$.

[33] Prat, J., Antonijuan, J., Folch, A., Sala, A., Lucchetti, A., Sard, F., Manuel, A., 2008. A simplified model of the interaction of the trawl warps, the otterboards and netting drag. Fisheries Research 94, 109117.

[34] Priour, D., 2003. Analysis of nets with hexagonal mesh using triangular elements. International Journal Numerical Methods in engineering 56, 1721-1733.

[35] Reite, K.J., 2006. PhD:Modeling and control of trawl systems. Ph.D. thesis. Norwegian University of Science and Technology, Trondheim.

[36] Reite, K.J., Sorensen, A., 2006. Mathematical modeling of the hydrodynamic forces on a trawl door. Journal of Ocean Engineering 31, 432-453.

[37] Sala, A., Lucchetti, A., Buglioni, G., 2007a. The influence of twine thickness on the size selectivity of polyamide codends in a Mediterranean bottom trawl. Fisheries Research 83, 192-203.

[38] Sala, A., Lucchetti, A., Palumbo, V., Hansen, K., 2007b. Energy saving trawl in mediterranean demersal fisheries, in: Soares, G., Kolev (Eds.), Ocean Engineering and Coastal Resources, Taylor \& Francis Group, London. pp. 961-964.

[39] Sala, A., Prat, J., Antonijuan, J., Lucchetti, A., 2009. Performance and impact on the seabed of an existing and an experimental otterboard: comparison between model testing and full-scale sea trials. Fisheries Research 100, 156-166.

[40] Schlichting, H., Gersten, K., 2000. Boundary layer theory. SpringerVerlag, Berlin Heidelberg. 
[41] Schumacher, W., 1974. Untersuchungen zum statischen und dynamischen verhalten des fangerättes schleppnetz unter besonderer berü cksichtigung der scherbretter. Ph.D. thesis. University of Rostock.

[42] Stengel, H., Hartung, F., 1964. Ergebnisse von windkanaluntersuchungen an scherbrettmodellen. Schiffbautechnik 14, 37-41.

[43] Strickland, A., 1995. Guidelinea for the construction and rigging of common steel vee doors. The Seafish Industry Authory.

[44] Suzuki, K., Takagi, T., Shimizu, T., Hiraishi, T., Yamamoto, K., Nashimoto, K., 2003. Validity and visualization of a numerical model used to determine dynamic configurations of fishing nets. Fisheries Science 69, 695-705.

[45] Takahashi, Y., Fujimori, Y., Hu, F., Shen, X., Kimura, N., 2013. HydroDynamic characteristics of the otterboard by CFD approach. Contributions on the Theory of Fishing Gears and Related Marine Systems Vol. 8. Paschen, M.

[46] Tauti, M., 1934. A relation between experiments on model and on fullscale of fishing net. Nippon Suissan Fakkaishi 3, 171-177.

[47] Valdemarsen, J., Misund, O., 1995. Trawl designs and techniques used by Norwegian research vessels to sample fish in the pelagic one. Editor Hylen, A. Proceedings of 6th IMR-PINRO symposium, Bergen, Norway.

[48] Vincent, B., Marichal, D., 2006. Modelling the dynamics of trawl doors in a trawl gear, in: Lee, C.W. (Ed.), Contributions on the Theory of Fishing Gears and Related Marine Systems Vol. 4, pp. 71-79.

[49] Wan, R., Hu, F., Tokai, T., 2002. A static analysis of the tension and configuration of submerged plane nets. Fisheries Science 68, 815-823.

[50] Ward, J., Ferro, R., 1993. The modeling of single-boat, mid-water trawl systems for fishing simulation. Fisheries Research 17, 311-331. 


\begin{tabular}{lccl}
\hline name & symbol & relations & description \\
\hline scale & $s f$ & & scale factor from model to full-scale \\
chord & $l$ & & mean hydrodynamic chord of the model \\
span & $b$ & $=b_{b} \cos \Lambda_{b}+b_{t} \cos \Lambda_{t}$ & distance from bottom to top flap tip \\
area & $S$ & $=b l$ & projected area of the foil \\
aspect ratio & $A R$ & $=b^{2} / S=b / l$ & \\
flap span & $b_{b}\left(b_{t}\right)$ & & bottom (top) tip-to-root flap distance \\
dihedral & $\Lambda_{b}\left(\Lambda_{t}\right)$ & & bottom (top) flap angle with chord line \\
attachment & $\left(\xi_{x}, \xi_{y}, \xi_{z}\right)$ & attachment bolt position and length
\end{tabular}

Table 1: Geometrical parameters of the model

a)

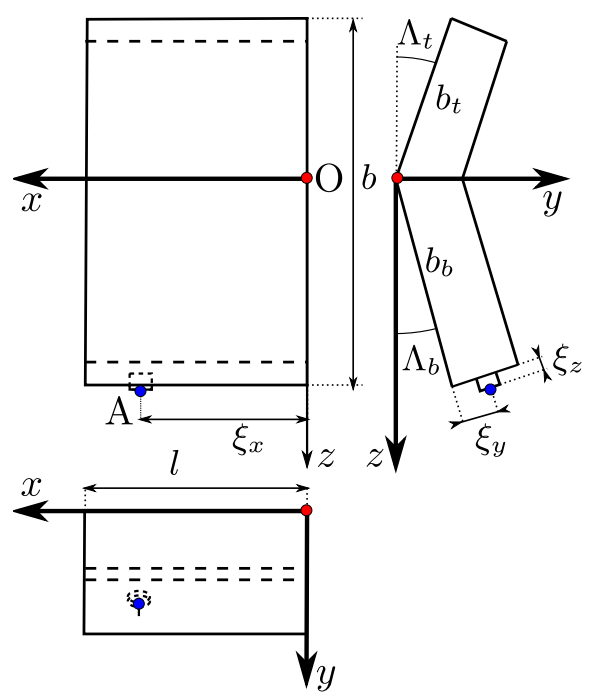

b)

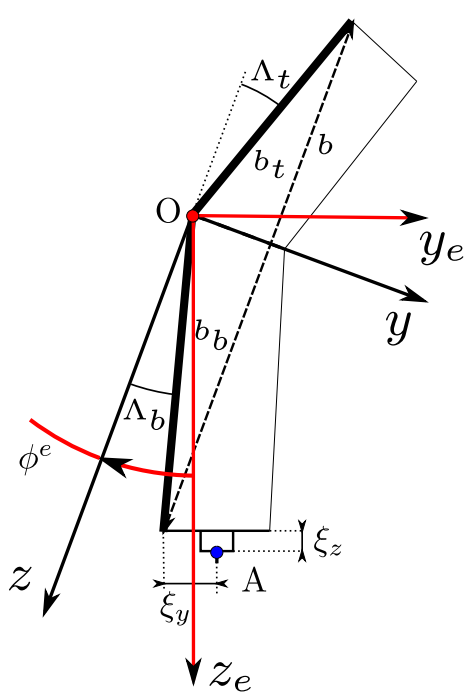

Figure 1: a) Schematic drawing of side, rear and top views of the trawl door model with all geometrical parameters indicated (body frame). b) Installation of the otter board in the wind tunnel with a roll angle $\phi^{e}$ (wind tunnel and body frames). 
a)

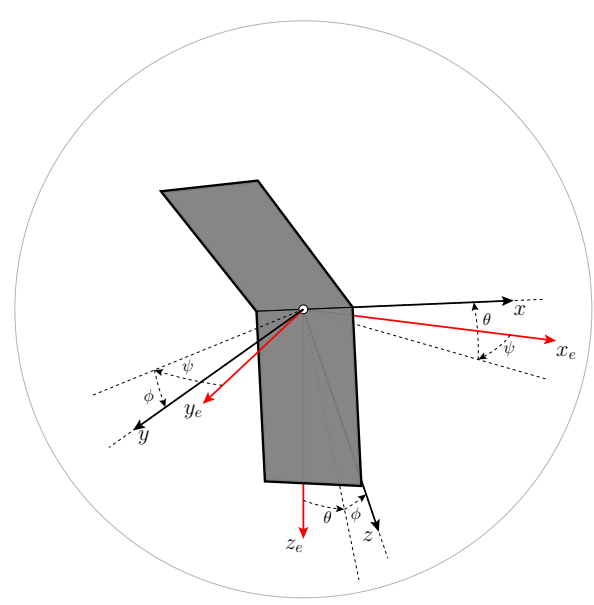

b)

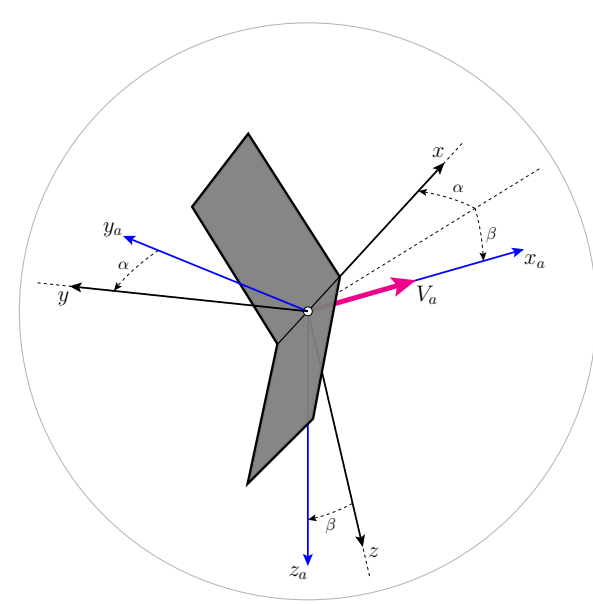

Figure 2: a) Earth to body reference frame change. b) Aerodynamic to body reference frame change.

a)

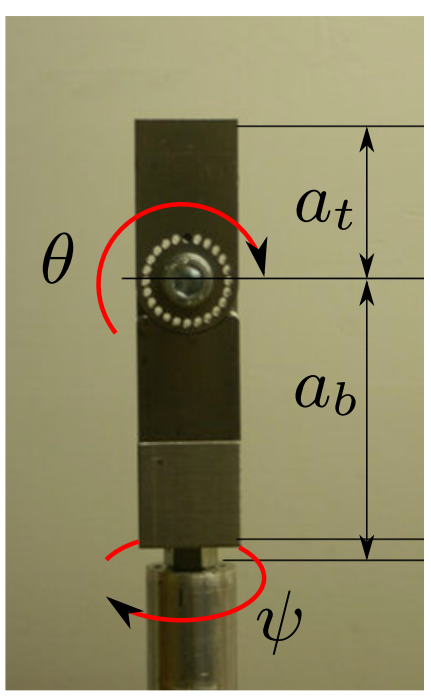

b)

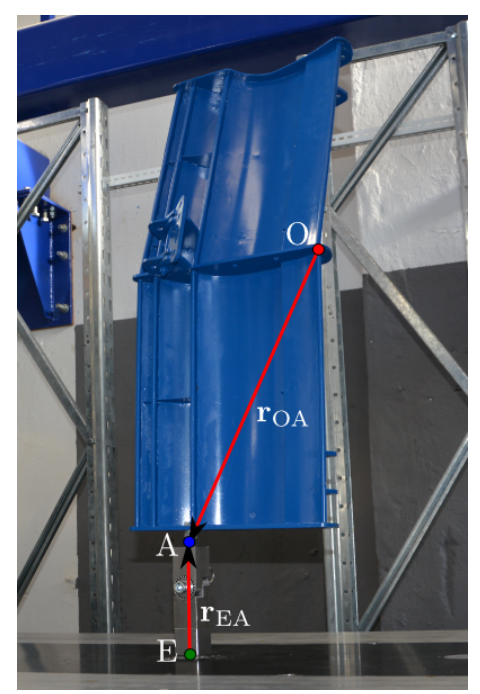

Figure 3: a) Picture of the adapter and the orientation angles $(\psi, \theta)$ of adapter. b) Picture of an otter board installed on the adapter. 


\begin{tabular}{lcl}
\hline name & symbol & description \\
\hline nominal velocity & $V_{n}$ & intended velocity \\
nominal yaw & $\psi_{n}$ & intended yaw angle \\
nominal pitch & $\theta_{n}$ & intended pitch angle \\
actual velocity & $V$ & actual velocity (from $\Delta p)$ \\
actual yaw & $\psi$ & actual yaw angle \\
actual pitch & $\theta$ & actual pitch angle $\left(\theta=\theta_{n}\right)$ \\
vector force & $\mathbf{F}^{e}$ & vector force in Earth frame \\
vector moment & $\mathbf{M}_{\mathbf{E}}^{e}$ & vector moment in Earth frame ${ }^{2}$ \\
pressure drop & $\Delta p$ & pressure drop in nozzle \\
air pressure & $p$ & barometric pressure \\
air temperature & $T$ & temperature
\end{tabular}

Table 2: List of wind tunnel output raw data.

\begin{tabular}{l|rrrrrrrrr}
$\alpha\left(^{\circ}\right)$ & 0 & 5 & 10 & 15 & 20 & 25 & 30 & 35 & 40 \\
\hline$x_{C P} / l$ & -0.262 & 0.088 & 0.360 & 0.438 & 0.493 & 0.532 & 0.561 & 0.583 & 0.604 \\
$y_{C P} / l$ & -0.166 & -0.019 & 0.089 & 0.107 & 0.116 & 0.120 & 0.124 & 0.125 & 0.126
\end{tabular}

Table 3: Relative position (in units of chord $l$ ) of the centre of pressure as a function of the angle of attack $\alpha$ for $\beta=0^{\circ}$. $\left(x_{C P}, y_{C P}\right)$ are given in body coordinates. 

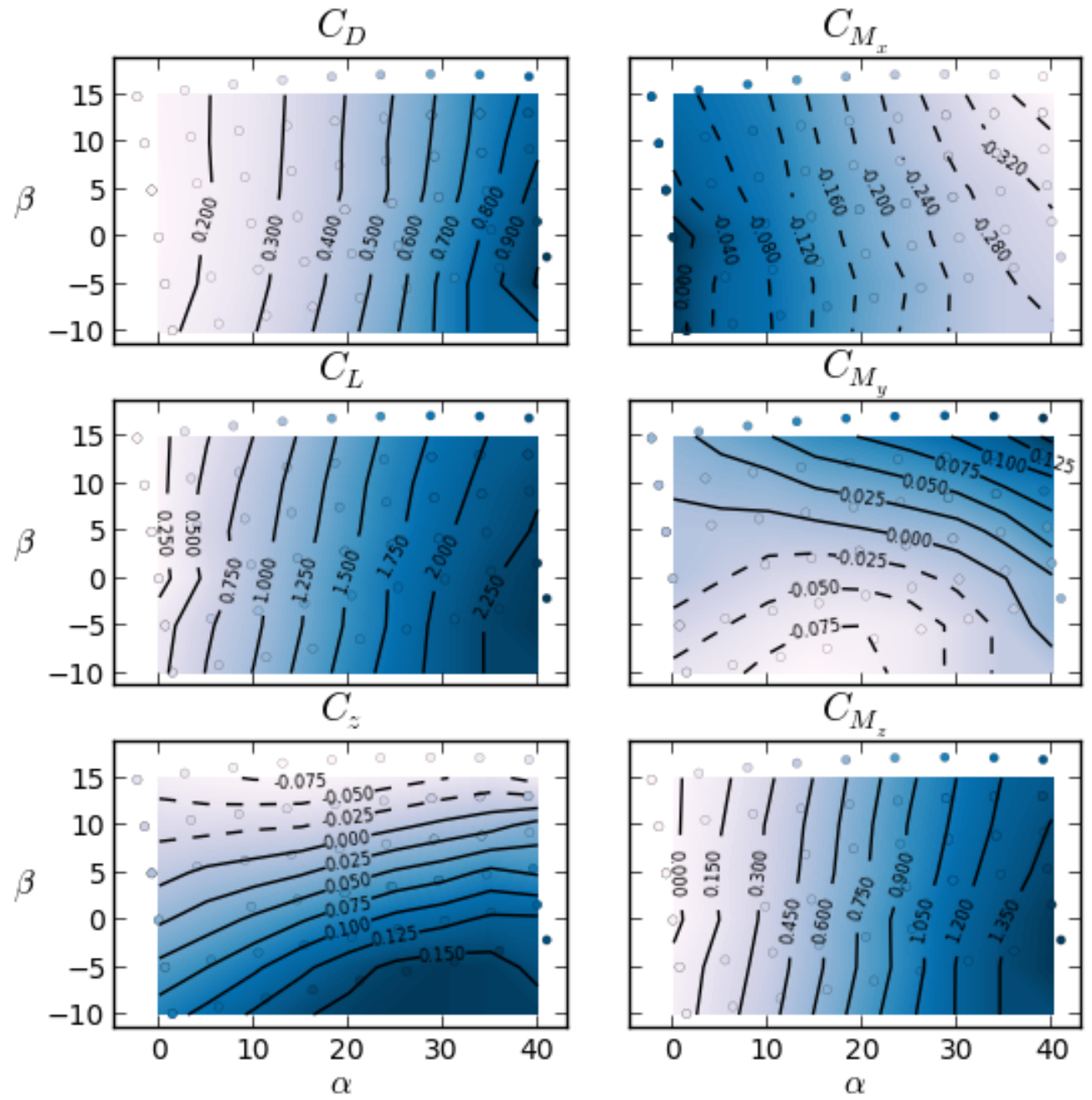

Figure 4: Contour maps of the aerodynamic coefficients of Thyborøn 15 vf model as a function of the aerodynamic angles. The actual experimental points are indicated with filled coloured circles. Contour levels are labeled with interpolated values of the coefficients. 
(a)

(b)
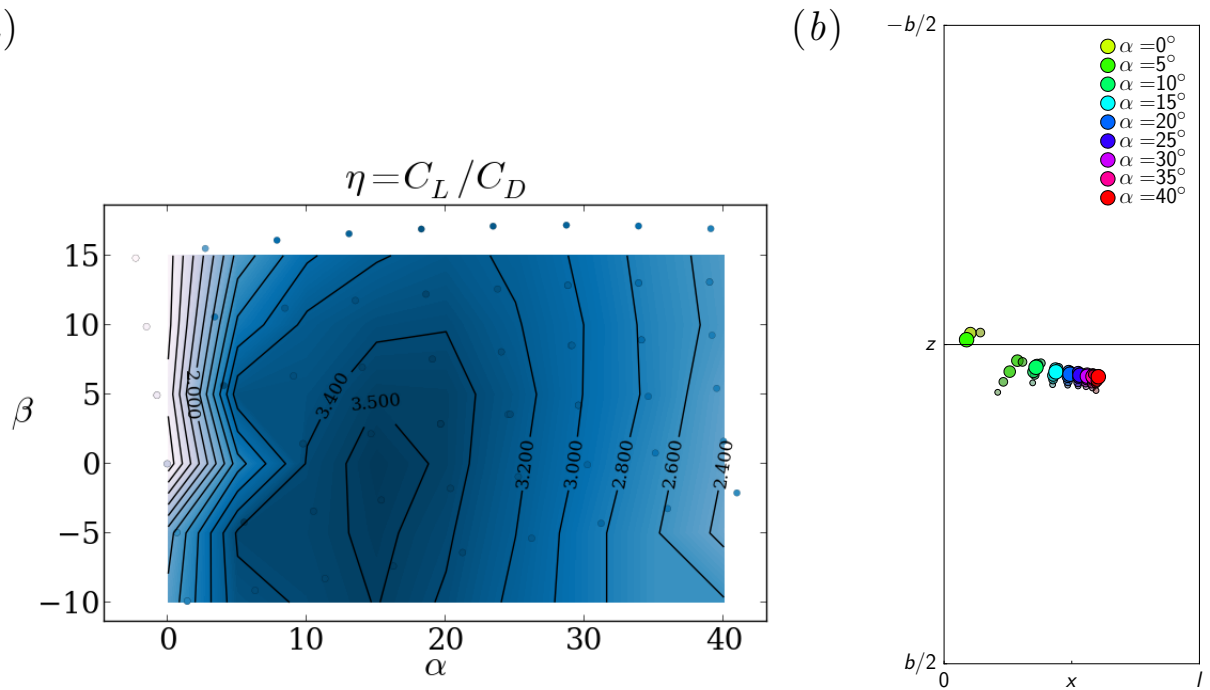

Figure 5: (a) Contour map of the efficiency $\left(\eta=C_{L} / C_{D}\right)$ of Thyborøn 15 vf model as a function of the aerodynamic angles. (b) Location of the centre of pressure on the trawl door plane as a function of angle of attack (colour coding, as shown in the legend) and sideslip angle (sizing, the largest corresponding to $\alpha=0^{\circ}$ ).

(a)

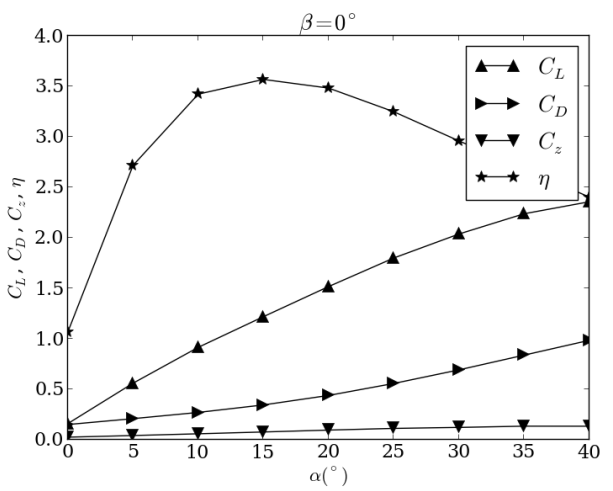

(b)

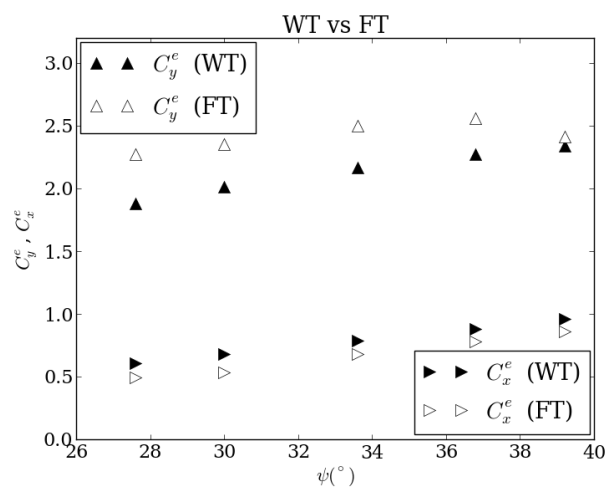

Figure 6: $(a)$ Force coefficients $\left(C_{L}, C_{D}\right.$ and $\left.C_{z}\right)$ and efficiency $(\eta)$ as a function of angle of attack for no sideslip angle. (b) Force coefficients comparison of wind tunnel (full symbols, WT) and flume tank (empty symbols, FT) results for the Thyborøn 15 vf model. 